\title{
Experimental testing and numerical simulations of blast-induced fracture of dolomite rock
}

\author{
Paweł Baranowski (D) - Lukasz Mazurkiewicz • Jerzy Małachowski • \\ Mateusz Pytlik
}

Received: 19 November 2019/Accepted: 2 August 2020/Published online: 18 August 2020

(C) The Author(s) 2020

\begin{abstract}
In this paper, the Johnson-Holmquist II (JH-2) model with parameters for a dolomite rock was used for simulating rock fragmentation. The numerical simulations were followed by experimental tests. Blast holes were drilled in two different samples of the dolomite, and an emulsion high explosive was inserted. The first sample was used to measure acceleration histories, and the cracking pattern was analyzed to perform a detailed study of the blastinduced fracture to validate the proposed method of modelling and to analyze the capability of the JH-2 model for the dolomite. The second sample was used for further validation by scanning the fragments obtained after blasting. The geometries of the fragments were compared with numerical simulations to further validate the proposed method of modelling and
\end{abstract}

P. Baranowski $(\bowtie) \cdot$ Ł. Mazurkiewicz $\cdot$ J. Małachowski Institute of Mechanics \& Computational Engineering, Faculty of Mechanical Engineering, Military University of Technology, 2 Gen. S. Kaliskiego Street, 00-908 Warsaw, Poland

e-mail: pawel.baranowski@wat.edu.pl

Ł. Mazurkiewicz

e-mail: lukasz.mazurkiewicz@wat.edu.pl

J. Małachowski

e-mail: jerzy.malachowski@wat.edu.pl

\section{Pytlik}

Central Mining Institute, Conformity Assessment Body, 40-166 Katowice, Poland

e-mail: mpytlik@gig.eu the implemented material model. The outcomes are promising, and further study is planned for simulating and optimizing parallel cut-hole blasting.

Keywords JH-2 constitutive model - Rock · Blasting · Fragmentation · FFT

\section{Introduction}

High explosives (HEs) are widely used in civil engineering and the mining industry for controlled fragmentation and rock removal [1, 2]. However, dozens of tests are needed to analyze, fully understand and optimize the process, which is costly and timeconsuming. As a result, it is only possible to determine the burden. Available field data are insufficient, as several elements must be included in the process: number of drilled blast holes, their positions, delay intervals, amount of HE used or behavior and response of the rock itself [3]. Numerical simulations can be implemented to overcome these deficiencies and have proved robust and efficient for modelling almost every problem in the field of engineering [4-11].

The blast-induced fracture of rock has been modeled and simulated by many authors [12-14]. Several scenarios at different scales, including small-scale blasting testing [15-18], bench and cutting blasting $[12,14,19,20]$, and large-scale modeling and simulations, e.g., mines [19, 21-23], have been 
considered. To simulate the fracture phenomenon, numerous different computational techniques can be implemented to reproduce the dynamic behavior of rock or other brittle materials. Mesh-based methods can be effectively used but must consider additional factors when dealing with large deformation in the model, e.g., regularization, erosion criteria, softening, and remeshing [24-26]. The problem of significant element distortion can be omitted by using different methods, e.g., the arbitrary Lagrangian-Eulerian (ALE) formulation [15, 18, 27], discrete element method (DEM) [28, 29] or mesh-free methods like smooth particle hydrodynamics $(\mathrm{SPH})[23,30]$. It is also possible to couple different techniques; such an approach has proved efficient and reliable in the case of blast-induced brittle fracture [17, 23, 28], as well as other engineering problems [31-33].

Regardless of the method used to simulate the problem, the material behavior needs to be reproduced reliably in order to ensure that the results are correct and comparable to actual data. Therefore, a constitutive model that captures damage, cracking and other physical and mechanical properties as comprehensively as possible is needed [15, 34, 35]. Several models are available for the response of brittle materials, especially rock. The most commonly used are the Johnson-Holmquist Concrete model (JHC model; sometimes referred to as the HolmquistJohnson-Cook model) [36, 37], the brittle damage model [22, 38], the Federal Highway Administration (FHWA) soil model [13, 39], the Riedel-HiermaierThoma (RHT) model [3, 40], the Continuous Surface Cap (CAP) model [38, 41], and the Karagozian and Case Concrete (KCC) model [42, 43]. Among constitutive models, the Johnson-Holmquist II (JH-2) model has been extensively used to reproduce the behavior of brittle and geomaterials under dynamic or impact loading conditions [15, 18, 44-51].

In this study, the blast fragmentation of a dolomite rock was experimentally and numerically studied. The field tests were reproduced with numerical simulations adopting explicit LS-Dyna code. Two different samples of the dolomite were considered. In each sample, blast holes were drilled, filled with emulsion $\mathrm{HE}$ inserted in the bottom of the sample, and covered with stemming. The first sample was used to measure the acceleration histories to conduct a detailed study of the blast-induced fracture of the rock to validate the proposed method of modelling and to analyze the capability of the JH-2 model for the dolomite. Additionally, the damping properties of the rock material were evaluated. The second sample was used to thoroughly analyze fragmentation quantitatively and qualitatively using the scanned fragments. For the numerical analyses, the finite element method (FEM) and SPH were used to represent the dolomite rock and the HE with stemming, respectively.

\section{Experimental procedure of the fragmentation test Equation Section (Next)}

The experimental tests presented in this paper are part of a wider project and only the results obtained from the two samples of dolomite are presented and discussed here. Sample no. 1 had a volume of approximately $0.364 \mathrm{~m}^{3}$ and a mass of $\sim 965.0 \mathrm{~kg}$ (Fig. 1), whereas sample no. 2 had a volume of $0.472 \mathrm{~m}^{3}$ and a mass of $\sim 1240.0 \mathrm{~kg}$ (Fig. 2). In both samples, a blast hole with a diameter of $30.0 \mathrm{~mm}$ and depth of $430.0 \mathrm{~mm}$ was drilled near the center. In the bottom of the hole, an emulsion HE was inserted with a mass of $10.0 \mathrm{~g}$. Emulsion explosives are the second most commonly used explosive type worldwide [52] and are commonly used in Polish underground mine operations $[1,53]$. Some of the physical properties of the HE are presented in Table 2. The blast hole was filled with stemming. In all cases, the blasting process was recorded using a Go-Pro camera.

The first test was conducted to validate the proposed methodology of modelling as well as the JH-2 constitutive model for the dolomite. For this purpose, vertical acceleration histories were recorded using PCB piezoelectric gauges with a measurement range of up to $100,000 \mathrm{~g}$. The gauges were attached to a steel ring, which was fixed to the rock sample using glue. Both sensors were placed in line from the blast hole: sensor A at a distance of $330 \mathrm{~mm}$ and sensor B at a distance of $530 \mathrm{~mm}$ from the hole. The sensors were connected to a SIRIUS HS measuring amplifier, and the cracking characteristics were analyzed and compared with numerical simulations. To further validate the modelling method, the second test was conducted. Fragments of rock sample no. 2 were scanned using a 3D laser scanner, and the field results were compared with the outcomes of finite element analysis (FEA). 
(a)

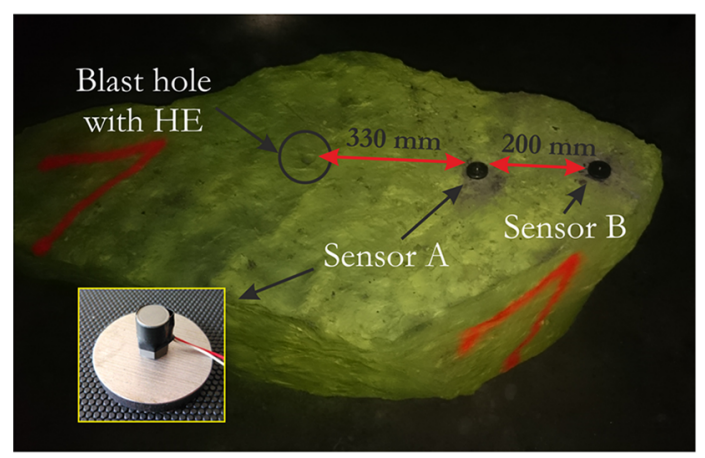

(b)

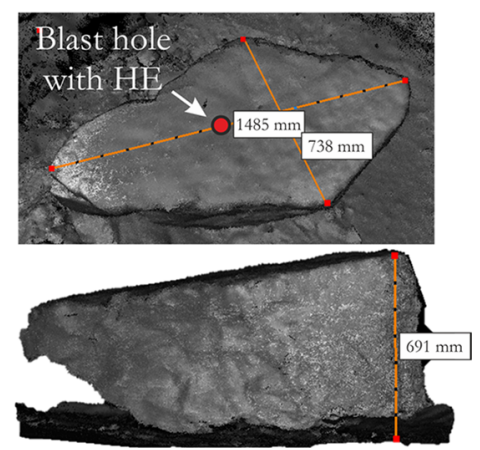

Fig. 1 Experimental set-up for fragmentation test no. 1: a the piece of the dolomite with the blast hole, $\mathbf{b}$ point cloud of the rock with characteristic dimensions

(a)

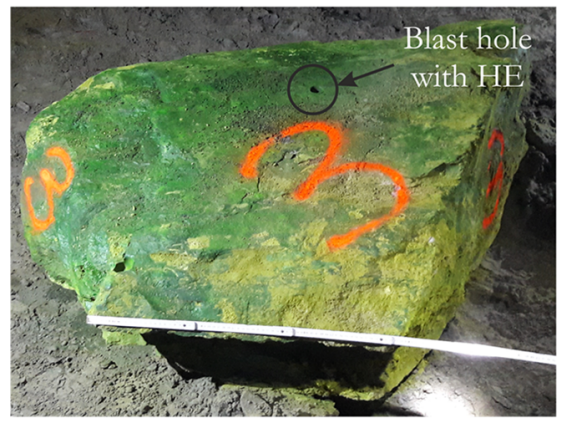

(b)

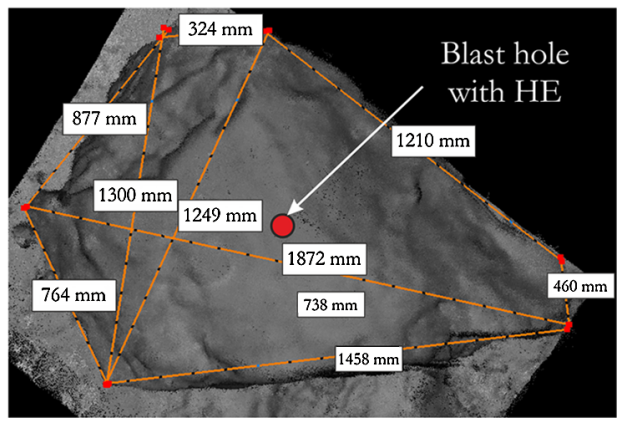

Fig. 2 Experimental set-up for fragmentation test no. 2: a the piece of the dolomite with the blast hole, b point cloud of the rock with characteristic dimensions

\section{Methodology for numerical simulation of the fragmentation test}

\subsection{Numerical integration procedure}

Numerical studies of the blast-induced fracture and fragmentation of the dolomite were carried out using FEM and SPH with an explicit integration procedure. Massively parallel processing (MPP) LS-Dyna code, which uses explicit central difference time integration, was adopted. The dynamic equation solved during the calculations has the following form [54]:

$M \ddot{x}_{n}=F_{n}^{e x t}-F_{n}^{\mathrm{int}}-C \dot{x}_{n}$,

where $M$ is the diagonal mass matrix; $F_{n}^{\text {ext }}$ is the external and body forces; $F_{n}^{i n t}$ is the stress divergence vector; $C$ is the damping matrix; and $x, \dot{x}$, $\ddot{x}$ are the nodal displacement, velocity and acceleration vectors.
Assuming that $\dot{x} \approx \dot{x}_{n-1 / 2}$, Eq. (3.1) is solved with numerical integration of acceleration $\ddot{x}_{n}$ :

$\ddot{x}_{n}=M^{-1}\left(F_{n}^{e x t}-C \dot{x}_{n-1 / 2}-F_{n}^{\mathrm{int}}\right)$,

Implementation of the central difference equations for velocity and displacement yields the following relations:

$$
\begin{gathered}
\ddot{x}_{n}=\frac{1}{\Delta t_{n}}\left(\dot{x}_{n+1 / 2}-\dot{x}_{n-1 / 2}\right) \Rightarrow \dot{x}_{n+1 / 2} \\
=\dot{x}_{n-1 / 2}+\Delta t_{n} \ddot{x}_{n}, \\
\dot{x}_{n+1 / 2}=\frac{1}{\Delta t_{n+1 / 2}}\left(x_{n+1}-x_{n}\right) \Rightarrow x_{n+1} \\
=x_{n}+\Delta t_{n+1 / 2} \dot{x}_{n+1 / 2},
\end{gathered}
$$

The main disadvantage of this method is that it is conditionally stable and requires a time step to be limited according to the Courant-Friedrichs-Lewy (CFL) stability condition [54]: 


$$
\Delta t=\frac{L_{E}}{Q+\sqrt{Q^{2}+c^{2}}},
$$

where $Q$ is a function of the viscous coefficients $C_{O}$ and $C_{1}$ and is formulated as follows:

$Q=\left\{\begin{array}{ll}C_{1} c+C_{0} L_{E}\left|\dot{\varepsilon}_{k k}\right| & \text { for } \dot{\varepsilon}_{k k}<0 \\ 0 & \text { for } \dot{\varepsilon}_{k k} \geq 0\end{array}\right.$,

where $L_{E}=V_{E} / A_{E \max }$ is the characteristic length of the element; $V_{E}$ is the volume of the element; $A_{E \max }$ is the largest side of the element area; and $c$ is the adiabatic speed of sound.

\subsection{SPH method}

The SPH method is a mesh-free particle method in which all computational properties, e.g., mass, position, and velocity, are associated with a particle. The description of the SPH continuum uses the principles of conservation of mass, momentum and internal energy as the governing equations in the Lagrangian description applied in FEM [55]:

$\frac{d \rho}{d t}=-\rho \frac{\partial v_{i}}{\partial x_{i}} ; \quad \frac{d v_{i}}{d t}=\frac{1}{\rho} \frac{\partial \sigma_{i j}}{\partial x_{j}} ; \quad \frac{d E}{d t}=\frac{\sigma_{i j}}{\rho} \frac{\partial v_{i}}{\partial x_{j}}$,

$\frac{\partial \rho_{p}}{\partial t}=\sum_{q=1}^{N} m_{q} v_{p q} \frac{\partial W_{p q}}{\partial x_{p}}$,

$\frac{\partial v_{p}}{\partial t}=\sum_{q=1}^{N} m_{q}\left(\frac{\sigma_{p}}{\rho_{p}^{2}}+\frac{\sigma_{q}}{\rho_{q}^{2}}\right) \frac{\partial W_{p q}}{\partial x_{p}}$,

$\frac{\partial E_{p}}{\partial t}=\sum_{q=1}^{N} m_{q} \frac{\sigma_{p} \sigma_{q}}{\rho_{p} \rho_{q}} v_{p q} \frac{\partial W_{p q}}{\partial x_{p}}$,

where $\sigma$ is stress; $v$ is velocity; $i j$ are indexes of components; $E$ is internal energy; $m$ is the mass of the particle; $W$ is a kernel function; $N$ is the number of particles within the smoothing length; and $p, q$ are indexes denoting different particles.

Equations (3.7) and (3.8) are solved by interpolation of a given function value $\langle f>$ (i.e., density, velocity, energy, etc.) at a given point based on the known value of this function at the surrounding points (particles) using the following formula [55]:

$$
\begin{aligned}
<f>(x) & =\int_{\Omega} f\left(x^{\prime}\right) W\left(x-x^{\prime}, h\right) d x^{\prime} \\
& \simeq \sum_{q=1}^{N} f\left(x_{q}\right) W\left(x-x_{q}, h\right) \Delta V_{q},
\end{aligned}
$$

where $\langle f\rangle$ is the function interpolation; $x$ is the vector defining the particle's position; $h$ is the maximum distance between particles (smoothing length); and $W$ is a kernel function.

In the LS-Dyna code, a cubic B-spline kernel with the following form is implemented [54]:

$$
W(R, h)=\alpha_{d}\left\{\begin{array}{ll}
\frac{2}{3}-R^{2}+\frac{1}{2} R^{3}, & 0 \leq R<1 \\
\frac{1}{6}(2-R)^{3}, & 1 \leq R<2 \\
0 & R \geq 2
\end{array},\right.
$$

where $R=\frac{r}{h}=\frac{\left|x-x^{\prime}\right|}{h}$ and $\alpha_{d}=\frac{1}{h} ; \frac{15}{7 \pi h^{2}} ; \frac{3}{2 \pi h^{3}}$ for the one-, two- and three-dimensional cases, respectively.

The smoothing length varies throughout the simulation. Therefore, the number of neighboring particles remains relatively constant and is obtained by recalculating the smoothing as follows:

$h=h_{0}\left(\frac{d_{0}}{d_{i}}\right)^{\frac{1}{p}}$,

or by solving the continuity equation:

$\frac{d h}{d t}=\frac{1}{d} \cdot \frac{h}{d} \cdot \frac{\partial d}{\partial t}$

where $d_{0}$ is the initial density, $h_{0}$ is the initial smoothing length, and $p$ is the dimension of space.

\section{Modelling and simulation of the fragmentation testEquation Section (Next)}

\subsection{Model definition}

The geometries of the three rock fragments were achieved based on the 3D laser scanning process from which the point cloud was obtained. As a result, discrete models were developed consisting of mainly 1-point nodal tetrahedron elements; however, brick elements with one integration point were also used within the area of the blast hole. In addition, SPH 
particles were used to describe the HE and stemming. During parallel studies, this FEM-SPH coupled model proved to be sufficiently effective and gave identical results for the test case compared with ALE modelling, which has been widely implemented for analyzing blast wave interactions with different types of structures [27, 56, 57]. The main advantage of the meshless approach is the significantly shorter computational time. In the LS-Dyna code, two fundamental approaches are available in which particles from different SPH parts can interact with each other. The default strategy is to use particle approximation to compute the inter-part particle interaction. However, when interpolation functions are used, numerical instabilities can arise. To treat SPH parts separately and simulate the interactions between them in parallel, penalty-based node-to-node contact can be introduced. Such an approach was implemented in the present study. On the other hand, a typical node-tosurface contact based on the penalty formulation was used between the SPH parts (HE and stemming) and the dolomite rock [58].

For the discretization of each rock, an average $5.0 \mathrm{~mm}$ mesh size was assumed for brick elements and tetragonal elements. This mesh was selected based on parallel numerical simulations of the rock dolomite subjected to blast loading. Ultimately, 20,332,016 and $21,350,000$ elements were used to represent sample no. 1 and no. 2 of the dolomite rock, respectively. The models with the initial boundary conditions are presented in Figs. 3 and 4. In the case of rock sample no. 1 , the vertical acceleration histories were measured in nodes representing the sensors in the experimental tests.

\subsection{Constitutive modelling}

\subsubsection{Rock dolomite}

In all cases, the dolomite was modelled using the $\mathrm{JH}-2$ model, which is based on the relation between normalized values of equivalent stress and pressure. The model is described with three surfaces that represent intact, damaged and fractured states of the material (Fig. 5). The normalized intact strength of the material presented in Fig. 5 is described using the following formula [44, 45]:

$\sigma *_{I}=A(P *+T *)^{N}(1+C \cdot \ln \dot{\varepsilon} *)$

where $\sigma *_{I}=\sigma_{I} / \sigma_{H E L}$ is the normalized intact strength ( $\sigma_{I}$ is the current equivalent stress, and $\sigma_{H E L}$ is the equivalent stress at the Hugoniot elastic limit (HEL)); $A, N$ are intact material constants; $C$ is the strain rate coefficient; $P *=P / P_{H E L}$ is the normalized hydrostatic pressure ( $P$ is the current hydrostatic pressure, and $P_{H E L}$ is the pressure at the HEL); $T *=T / P_{H E L}$ is the normalized maximum tensile hydrostatic pressure; and $\dot{\varepsilon} *=\dot{\varepsilon} / \dot{\varepsilon}_{0}$ is the dimensionless strain rate $(\dot{\varepsilon}$ is the current equivalent strain rate, and $\dot{\varepsilon}_{0}=1.0 \mathrm{~s}^{-1}$ is the reference strain rate).

The damaged material is represented with a dashed line in Fig. 5 and is determined by [44, 45]:

$\sigma *_{D}=\sigma *_{I}-D\left(\sigma *_{I}-\sigma *_{F}\right)$

where $D$ is a damage factor and takes a value between 0 and 1 . The normalized fractured strength of the material is represented by $\sigma *_{F}$ and is described using the following formula [44, 45]:

$\sigma *_{F}=B(P *)^{M}(1+C \cdot \ln \dot{\varepsilon} *)$

where $B, M$ are the fractured material constants.

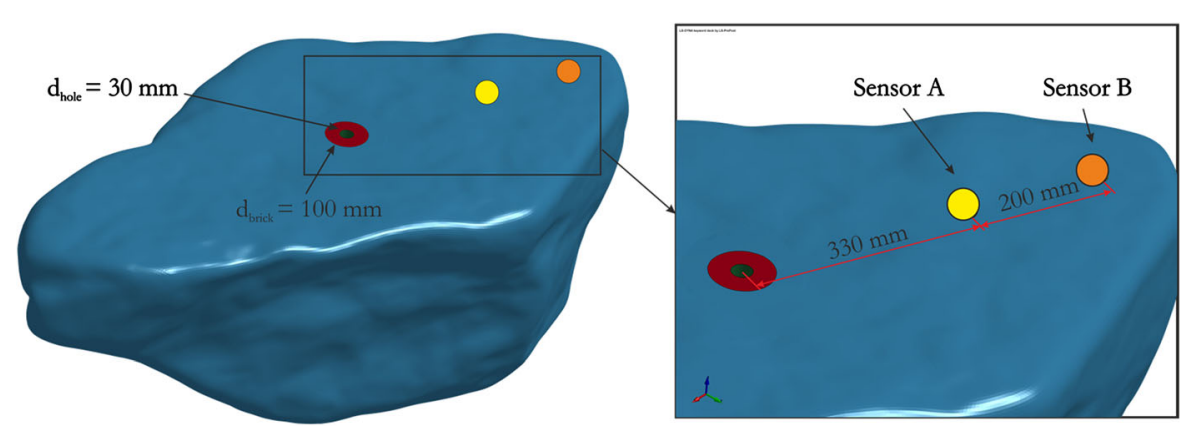

Fig. 3 Numerical model of dolomite rock sample no. 1 with a close-up view of the acceleration gauge placement 


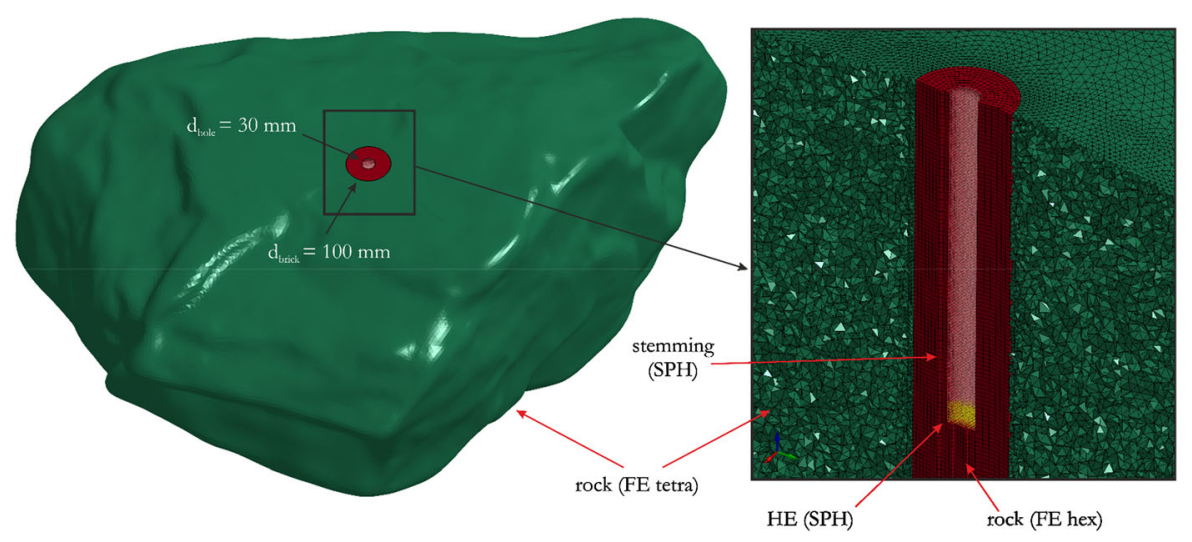

Fig. 4 Numerical model of dolomite rock sample no. 2 with a close-up view of the blast hole with stemming and HE

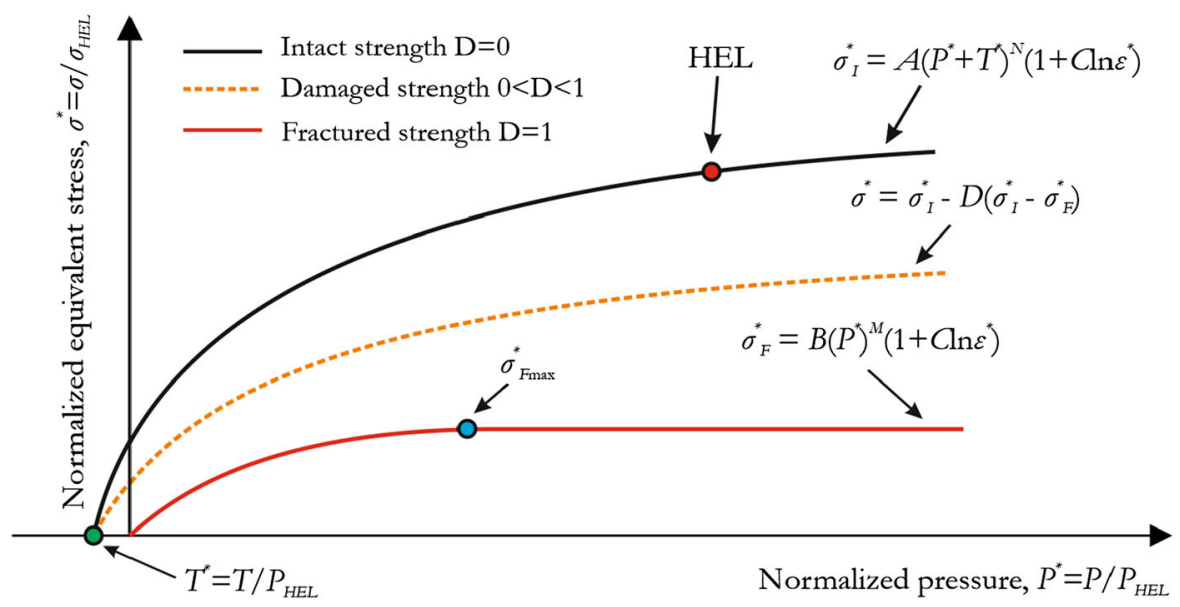

Fig. 5 Intact, damaged and fractured surfaces describing the JH-2 constitutive model [59]

In Fig. 5, $\sigma *_{F M a x}$, which represents the maximum value of $\sigma *_{F}$, can be observed. This parameter makes it possible to control the upper limit of the fracture strength. The formulas above characterize the behavior of the material described with the JH-2 constitutive model. When the value of equivalent stress is larger than $\sigma *_{I}$, the material starts to deform plastically (Eq. 4.1). Then, damage to the material starts to accumulate, and its strength decreases until it reaches the damage surface $\sigma *_{D}$ (Eq. 4.2). In this state, the material is partially damaged $(0 \leq D \leq 1)$. The softening continues until the material is fully damaged, which means that the value of damage parameter $D$ equals 1.0 and the material is characterized by the fractured material surface (Eq. 4.3). The damage is calculated as follows $[44,45]$ :
$D=\sum \frac{\Delta \varepsilon_{P}}{\Delta \varepsilon_{P}^{F}}$

where $\Delta \varepsilon_{P}$ is the increment of the equivalent plastic strain during a calculation cycle and $\varepsilon_{P}^{F}$ is the equivalent fracture plastic strain given by $\varepsilon_{P}^{F}=$ $D_{1}(P *+T *)^{D_{2}}\left(D_{1}, D_{2}\right.$ - damage constants).

The procedure for determining $\mathrm{JH}-2$ constants is not a straightforward task and is not the main topic of the study; thus, only a brief discussion is included. Please see [59] for a detailed description of the procedure for determining JH-2 constants. In Table 1, the JH-2 parameters for the dolomite are presented. In the present paper, a different dolomite was studied than in the authors' previous paper [27], and therefore some of the constants were modified. 
Table 1 Material properties for the $\mathrm{JH}-2$ constitutive model for dolomite
*Value should be adjusted based on mesh size

\begin{tabular}{lcc}
\hline Parameter & Value & Unit \\
\hline Density, $\rho$ & 2840.0 & $\mathrm{~kg} / \mathrm{m}^{3}$ \\
Poisson's ratio, $v$ & 0.24 & - \\
Bulk modulus, $K_{I}$ & $30,834.5$ & $\mathrm{MPa}$ \\
Shear modulus, $G$ & $19,059.6$ & $\mathrm{MPa}$ \\
Elastic modulus, $E$ & $47,410.3$ & $\mathrm{MPa}$ \\
Hugoniot elastic limit, $H E L$ & 2750.0 & $\mathrm{MPa}$ \\
HEL pressure, $P_{H E L}$ & 1945.0 & $\mathrm{MPa}$ \\
Maximum tensile strength ${ }^{*}, T$ & 29.2 & $\mathrm{MPa}$ \\
Intact strength coefficient, $A$ & 0.78 & - \\
Fractured strength coefficient, $B$ & 0.65 & - \\
Strain rate coefficient, $C$ & 0.02 & - \\
Intact strength exponent, $N$ & 0.45 & - \\
Fractured strength exponent, $M$ & 0.45 & - \\
Bulk factor, $\beta$ & 1.0 & - \\
Damage coefficient, $D_{1}$ & 0.001 & - \\
Damage coefficient, $D_{2}$ & 1.15 & - \\
Pressure coefficient $2, K_{2}$ & $700,000.0$ & $\mathrm{MPa}$ \\
Pressure coefficient $3, K_{3}$ & $5,650,000.0$ & $\mathrm{MPa}$ \\
Maximum normalized fracture strength, $\sigma^{*}{ }_{\text {max }}$ & 0.35 & - \\
\hline
\end{tabular}

\subsubsection{Stemming and high-explosive material models}

The HE was described using the Jones-Wilkins-Lee (JWL) equation of state and the High Explosive Burn constitutive model (HEB). The equation describing the behavior of detonation products has the following form [58]:

$$
\begin{aligned}
p= & A_{H E}\left(1-\frac{\omega}{R_{1} V}\right) e^{-R_{1} V}+B_{H E}\left(1-\frac{\omega}{R_{2} V}\right) e^{-R_{2} V} \\
& +\frac{\omega E_{o}}{V}
\end{aligned}
$$

where $V=\rho_{O} / \rho ; \rho_{O}$ is the initial density of the HE; $\rho$ is the actual density of the HE; $E_{O}$ is the detonation energy per unit volume and the initial value of $E$ of the $\mathrm{HE}$; and $A_{H E}, B_{H E}, R_{1}, R_{2}$, and $\omega$ are empirical constants determined for a specific type of explosive material based on experiments [60] using the Gurney energy, detonation pressure and explosion heat.

All required parameters of the HE used in the mining industry were defined based on the results of a so-called cylindrical test (Table 2). A detailed description of the test procedure can be found in [60]. The stemming was simulated using the FHWA soil model with the reported parameters of unsaturated sand (Table 3) [61] and supplemented with values from the literature [13, 39]. The FHWA soil model is efficient for modeling the behavior of soil or/and sand with the consideration of strain softening, strain rate effects, moisture content and kinematic hardening [13, 39]. Moreover, the FHWA material model is stable even if unconfined conditions occur.

\section{Results and discussion}

To investigate rock blasting and fragmentation, two different dolomite samples were considered. The first sample was used to measure acceleration histories for a detailed study of blast-induced fracture in order to validate the proposed modeling method and analyze the capability of the JH-2 model for the dolomite. Furthermore, damping properties were evaluated to 
confirm the proper dynamic response of the material. The second sample was used to analyze the fragmentation characteristics in detail using the scanned fragments to further validate the proposed method of modelling, the JH-2 material model and the correlated damping coefficients.

\subsection{Rock sample no. 1}

The main objective of the first stage was to compare the dynamic response of the rock material with the measurements from the field tests. Figure 6 presents the vertical acceleration histories for sensors A and B. The analysis of the results revealed that sensor A (closer to the blast hole), together with the steel ring, was detached from the rock mass immediately after the detonation of the HE (it was found next to the rock sample). Therefore, the gauge did not transfer any acceleration, and the results were rejected for further analysis. However, the signal from acceleration sensor B (farther from the blast hole) had a damped vibration characteristic. The first peaks, which occurred for $75 \mu$ s after detonation, were interference and were not taken into consideration for further study. Ultimately, the acceleration history from sensor B was used for comparison with the outcomes of the numerical simulations. However, before the validation analyses, the damping properties of the tested dolomite were calibrated.

Table 2 Material properties for HE with EOS [60]

\begin{tabular}{lrl}
\hline Parameter & \multicolumn{1}{l}{ Value } & Unit \\
\hline Initial density, $\rho_{O}$ & 1130.0 & $\mathrm{~kg} / \mathrm{m}^{3}$ \\
Detonation velocity, $D$ & 4805.0 & $\mathrm{~m} / \mathrm{s}$ \\
Chapman-Jouguet pressure, $p_{C J}$ & 7400.0 & $\mathrm{MPa}$ \\
$A_{H E}$ & $252,000.0$ & $\mathrm{MPa}$ \\
$B_{H E}$ & $15,570.0$ & $\mathrm{MPa}$ \\
$R_{1}$ & 6.08 & - \\
$R_{2}$ & 2.05 & - \\
$\omega$ & 0.25 & - \\
Detonation energy per unit volume, $E_{O}$ & 3700.0 & $\mathrm{MPa}$ \\
\hline
\end{tabular}

\subsubsection{Calibration of damping properties}

For dynamic analysis of rock blasting, the damping mechanism and its magnitude are crucial for obtaining reliable outcomes with a correct material response [62]. The damping in the numerical simulations should represent the energy loss in the system during blast wave propagation [63]. Given the mentioned phenomena, the Rayleigh classical approach, which is commonly used in FE dynamic analyses, was introduced in the present numerical simulations of blastinduced fracture of the dolomite $[64,65]$. According to Rayleigh theory, the damping matrix is a linear ombination of the mass and stiffness matrixes:

$C=\alpha M+\beta K$,

where $C$ is the damping matrix, $M$ is the diagonal mass matrix; $K$ is the stiffness matrix; $\alpha$ is the damping coefficient for mass-weighted damping; and $\beta$ is the damping coefficient for stiffness-weighted damping.

Determining the values of damping coefficients is quite difficult for rock-like and geomaterials due to the uncertain boundary conditions, especially initial cracks, heterogeneity and residual stress. Therefore, in the present paper, several coefficients of stiffnessweighted damping were tested for calibration purposes. Values of $\beta$ of $0.05,0.1,0.15,0.20$ and 0.25 were taken into consideration, and the obtained vertical accelerations for each case were compared with the actual outcomes (Fig. 7). The results show that the stiffness-weighted damping coefficient significantly influences the acceleration oscillations and energy loss caused by damping.

For a deeper analysis of the effect of damping on the obtained results, the Fast Fourier Transform (FFT) was used to quantitatively compare all waveforms (Fig. 8). The same sampling frequency and window size were used for each characteristic, including the experimental one. To assess feasible values of the stiffness-weighted damping coefficient, the maximum FFT magnitude for each $\beta$ was taken from Fig. 8 and compared with the actual outcomes (Fig. 9). The magnitudes were selected for frequencies less than $20 \mathrm{kHz}$. However, between 20 and $30 \mathrm{kHz}$, another dominant wave frequency occurred, which is clearly seen in the close-up view included in Fig. 8. This wave frequency was attributed to shock wave reflection from the ground on which the rocks were placed. In the numerical simulations, the ground was omitted. 
Table 3 Material properties for stemming described using MAT_FHWA_SOIL $[13,39,61]$

\begin{tabular}{lcl}
\hline Parameter & Value & Unit \\
\hline Density, $\rho_{s t}$ & 2350.0 & $\mathrm{~kg} / \mathrm{m}^{3}$ \\
Specific gravity, $S P G R A V$ & 2.65 & - \\
Density of water, $\rho_{\text {wat }}$ & 1000.0 & $\mathrm{~kg} / \mathrm{m}^{3}$ \\
Viscoplasticity parameter, $V_{n}$ & 1.1 & - \\
Viscoplasticity parameter, $\gamma_{r}$ & 0.0 & - \\
Max. number of plasticity iterations, $I T E R_{\text {max }}$ & 10.0 & - \\
Shear modulus, $G_{s t}$ & 19.5 & $\mathrm{MPa}$ \\
Bulk modulus, $K_{s t}$ & 15.3 & $\mathrm{MPa}$ \\
Peak shear strength angle, $\varphi_{\text {max }}$ & 0.42 & $\mathrm{radians}$ \\
Cohesion, $C O H$ & 0.011 & $\mathrm{MPa}$ \\
Eccentricity parameter, $E C C E N$ & 0.7 & - \\
Strain hardening $\%$ of $\varphi_{\max }$ where nonlinear effects start, $A_{n}$ & 0.0 & - \\
Strain hardening amount of non-linear effects, $E_{t}$ & 10.0 & - \\
Moisture content, $M C O N T$ & 6.2 & $\%$ \\
Parameter for pore water effects on bulk modulus, $P W D_{l}$ & 0.0 & - \\
Skeleton bulk modulus, $P W K S K$ & 0.153 & $\mathrm{MPa}$ \\
Parameter for pore water effects on confinement pressure, $P W D_{2}$ & 0.0 & - \\
Residual friction angle, $\varphi_{\text {res }}$ & 0.063 & radians \\
Volumetric strain at initial damage threshold, $D_{\text {int }}$ & 0.001 & - \\
Void formation (fracture) energy, $V_{d f m}$ & 10.0 & - \\
Level of damage causing element deletion, $D A M_{l e v}$ & 0.0 & - \\
Maximum principal failure strain, $E P S_{\text {max }}$ & 0.0 & - \\
\hline & & \\
\end{tabular}

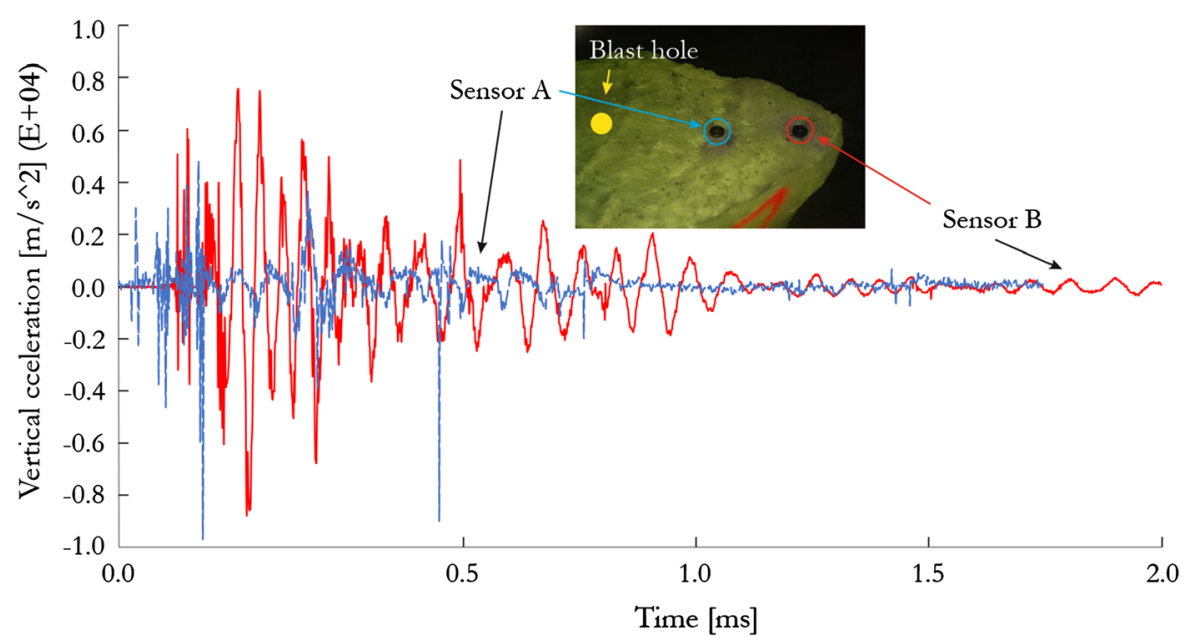

Fig. 6 Vertical acceleration from sensors A and B obtained from the experiment

Moreover, the gauges, steel rings and glue were not modelled, which could also affect the differences in the obtained waveforms. Ultimately, a satisfactory correlation of the maximum amplitude was obtained for $\beta$ equal to 0.20 , and this value was used for the validation and further numerical simulations. The mass-weighted damping $\alpha$ influences lower frequencies, and its impact on the results was insignificant in the cases in the present study. Consequently, the $\alpha$ coefficient was set to 1.0 in all FEA. 
In Fig. 10, the vertical acceleration vs. time characteristics obtained from the field test and the FEMSPH simulation with $\beta$ equals to 0.20 are presented and compared. The characteristics obtained from acceleration sensor B are reproduced quite well: the oscillations begin nearly at the same time as in the experimental test, and their duration is also similar (energy dissipation is comparable). In the numerical simulations, several simplifications were considered: isotropic, homogenic properties of the dolomite were used, and the ground and the sensors with steel rings were modelled.

An example of the pressure distribution within the rock for selected time moments is presented in Fig. 11. For a better visualization of the outcomes, the fringe was limited to $-25.0 \mathrm{MPa}$ and +25.0 $\mathrm{MPa}$, and the model was cut. During the initial moments, the shock wave travelled into the rock, resulting in compressive damage in the area close to the blast hole. Next, the shock wave travelled back and forth and was reflected from the outer surfaces of the rock.

The reproduction of the actual test was qualitatively analyzed based on the comparison of the characteristics of the cracks and fragments in the experimental test with those from the numerical simulations. Figure 12 presents the results of the simulation and actual test at the selected stage of the blasting process. The cracking characteristic was satisfyingly reproduced in the numerical modelling. The sudden expansion of the HE products resulted in crack formation. Although the major damage was caused by radial cracks, transversal cracking was also observed. Ultimately, dolomite rock sample no. 1 was divided into five main pieces. However, some small pieces of rock were observed in the area directly under the blast hole.

\subsection{Rock sample no. 2}

In the next stage of the study, the proposed method of modelling, the implemented JH-2 constitutive model, and the correlated damping properties were validated based on the blasting fragmentation test conducted with the second rock sample. The crack pattern is shown in Fig. 13. The cracks are represented in red color, which corresponds to a damage index of 1.0; this value indicates that the material is fully damaged. The results are presented for $0.01 \mathrm{~s}$ of simulation time. The rock was fragmented into two main pieces, one of which was smaller than the other. In the field test, the formation of cracks resulted in a loss of material continuity. This phenomenon was not reflected in the numerical simulations because an erosion criterion was not used (numerical method for removing finite elements from the model). To compare the geometries of the fragments obtained in the numerical simulations and experimental tests, 3D laser scanning was used. The resulting point cloud was used to calculate the volumes of the real-world fragments and the fragments from the numerical simulations. Figure 14 presents the numerical simulations and field tests of rock sample no. 2 after blasting. To better analyze the results, the fully damaged finite elements were blanked. Moreover, fragment no. 2 was manually

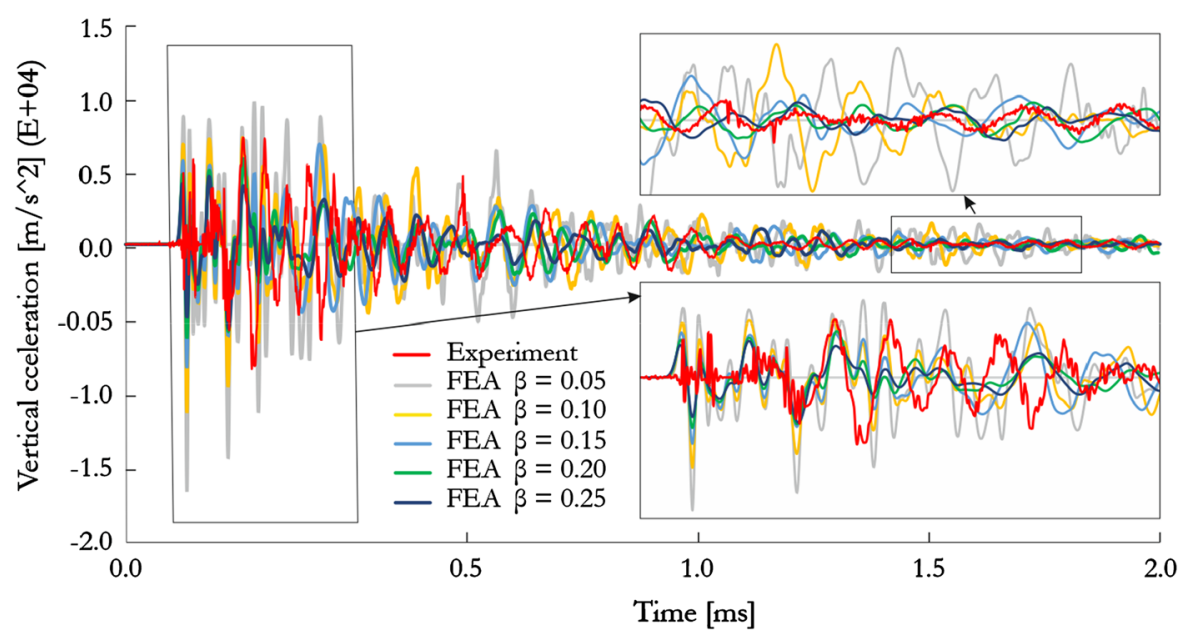

Fig. 7 Vertical acceleration from sensor B obtained from the experiment and FEA for different damping coefficients 


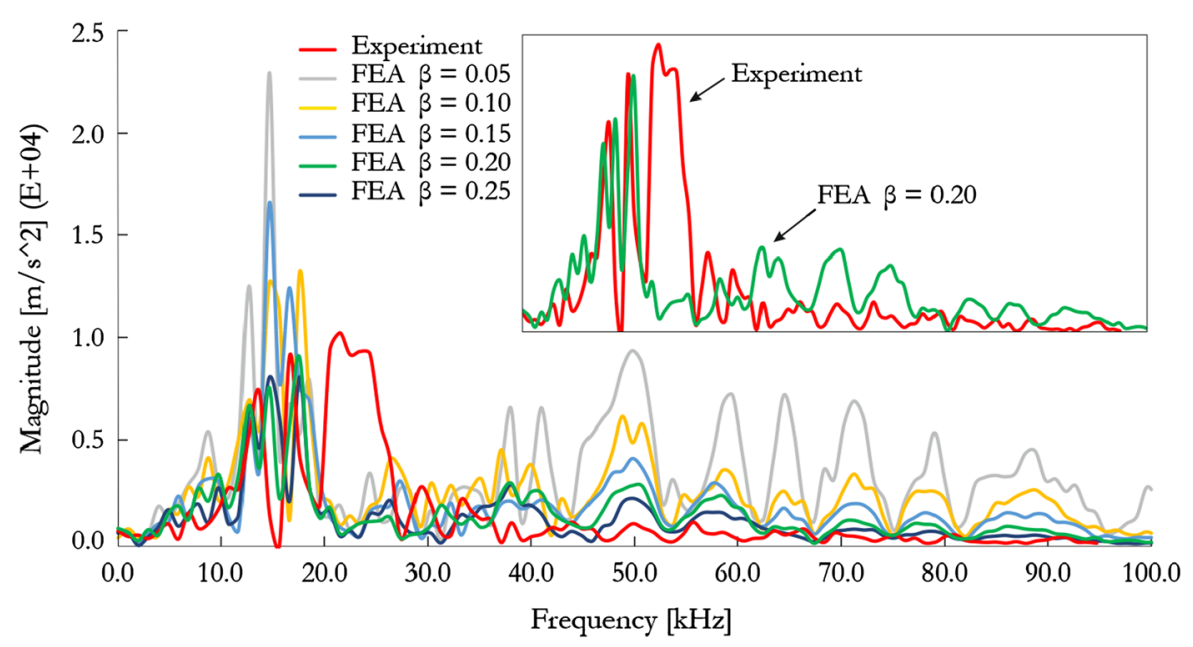

Fig. 8 FFT of the vertical acceleration from sensor B obtained from the experiment and FEA for different damping coefficients; closeup view of the comparison between FEA with $\beta$ equal to 0.20 and the experiment

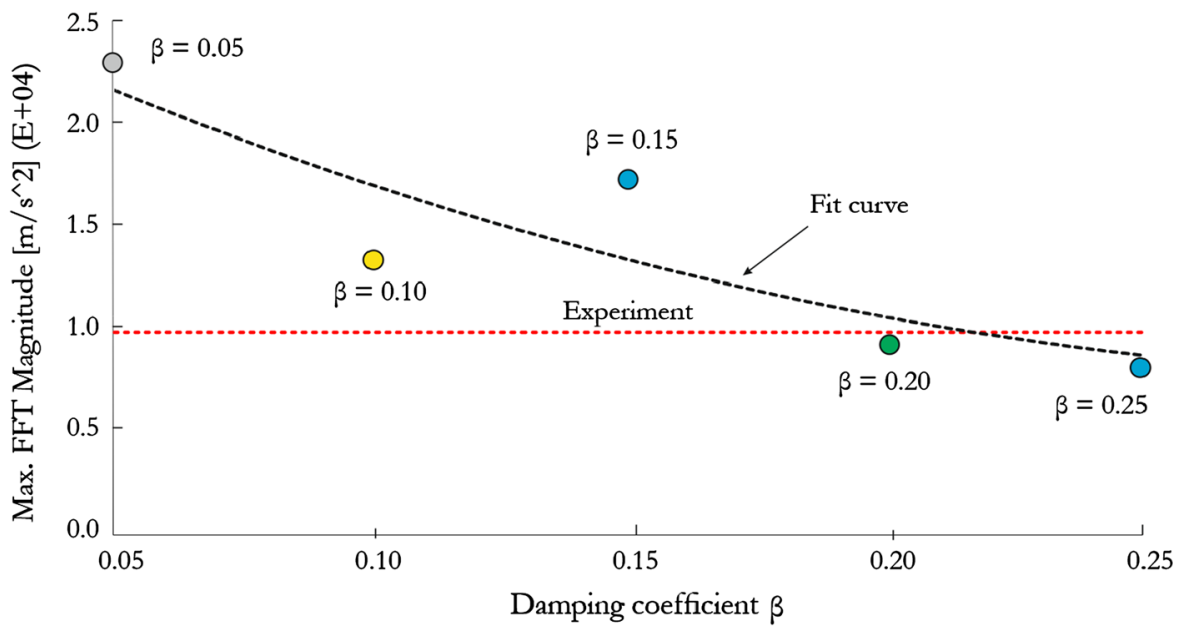

Fig. 9 Max. FFT for different damping coefficients and their influence on the obtained max. FFT magnitude

positioned similarly to the final position of the actual fragment to further improve the visualization of the results. Satisfactory similarity of the cracking pattern and the resulting geometries of the created rock fragments was observed.

Based on 3D laser scanning, the volumes of the obtained fragments were calculated and compared with their discrete representatives (Table 4). The volumes of fragment no. 1 obtained from the numerical simulations and actual test were nearly identical. However, higher errors were obtained for larger fragments. In general, the field results were satisfactorily reproduced. The discrepancies are attributable to the following factors:
- the smaller fragments visible in Fig. 14 were not measured.

- The fully damaged finite elements, which were blanked for volume calculations, were not taken into consideration.

- The fragments within the area under the HE were treated as parts of fragments no. 1 and no. 2 .

\section{Conclusions}

This paper presents experimental and numerical studies of blast fragmentation of two samples of a 


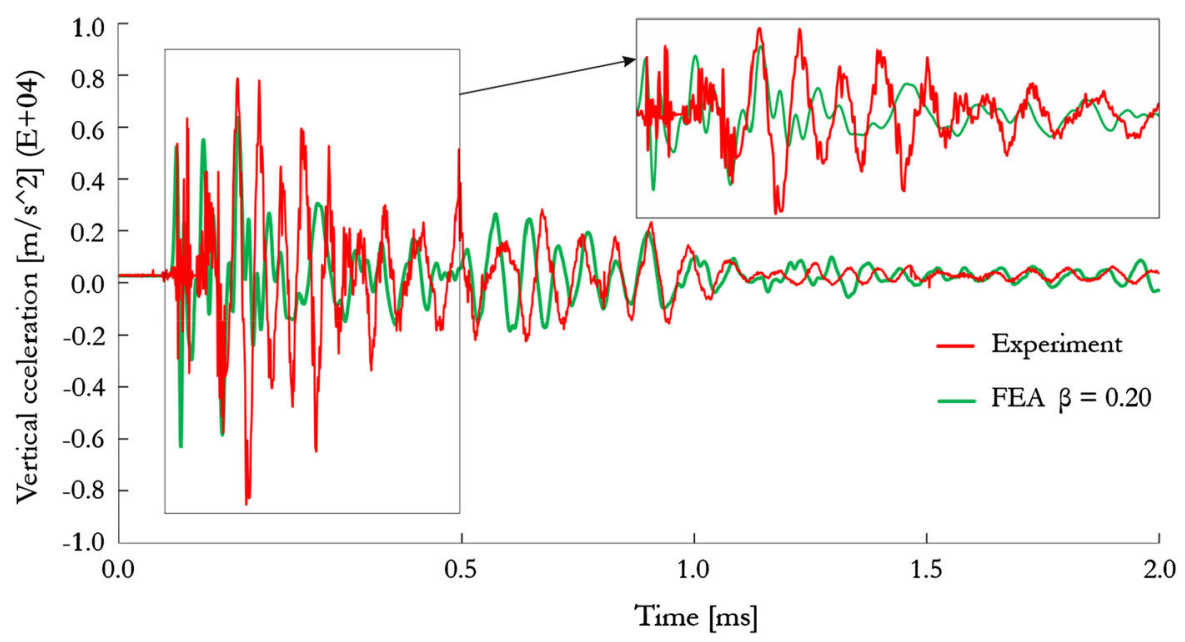

Fig. 10 Comparison of vertical accelerations obtained from sensor B in the experiment and the numerical simulation with $\beta$ equal to 0.20

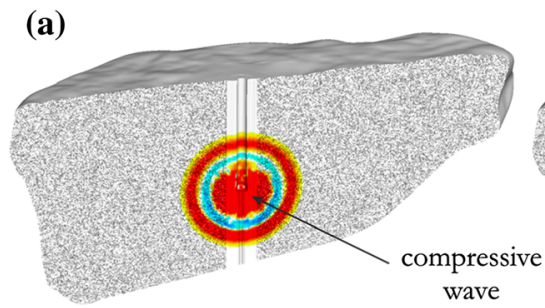

(b)

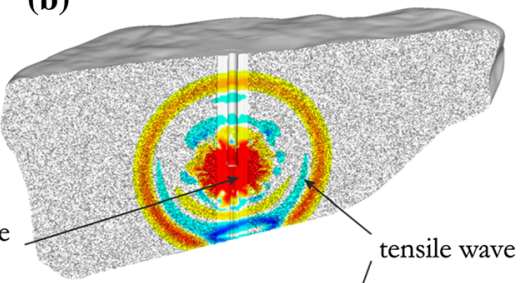

(c)

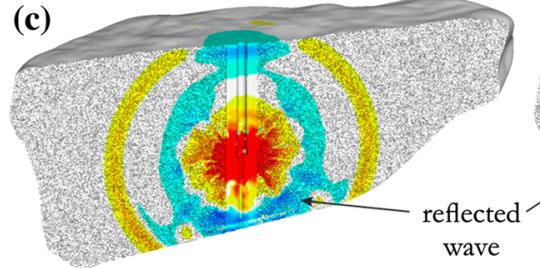

(d)

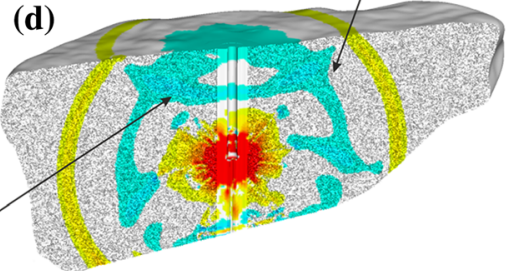

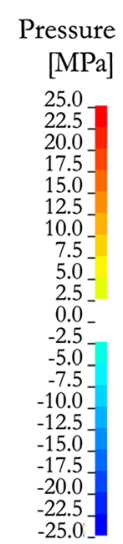

Fig. 11 Section view of the pressure distribution obtained from numerical simulations of the blasting fragmentation test of rock no. 1: a) $0.0003 \mathrm{~s}, \mathrm{~b}) 0.0005 \mathrm{~s}, \mathrm{c}) 0.0007 \mathrm{~s}, \mathrm{~d}) 0.0009 \mathrm{~s}$
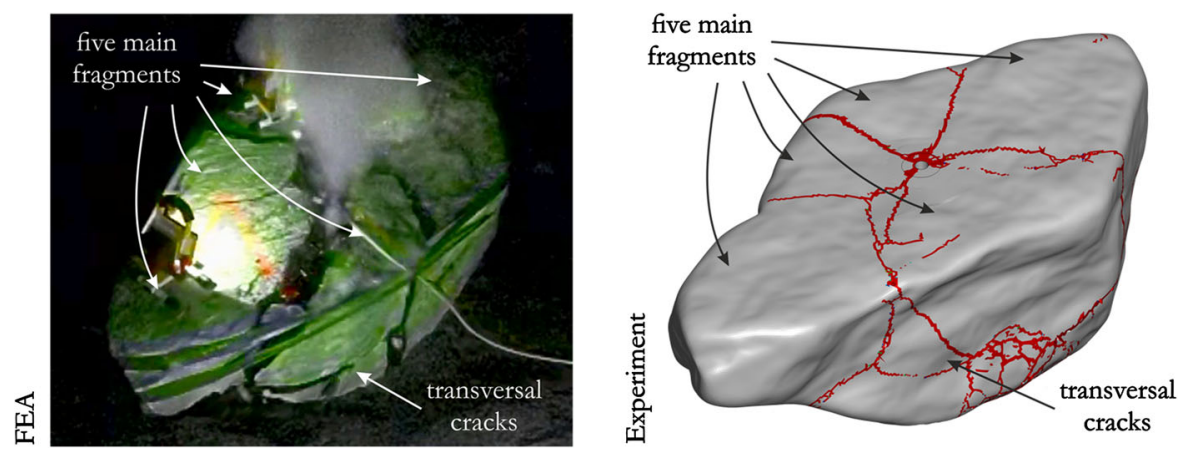

Fig. 12 Crack pattern obtained from numerical simulations of the blasting fragmentation test of sample no. 1 

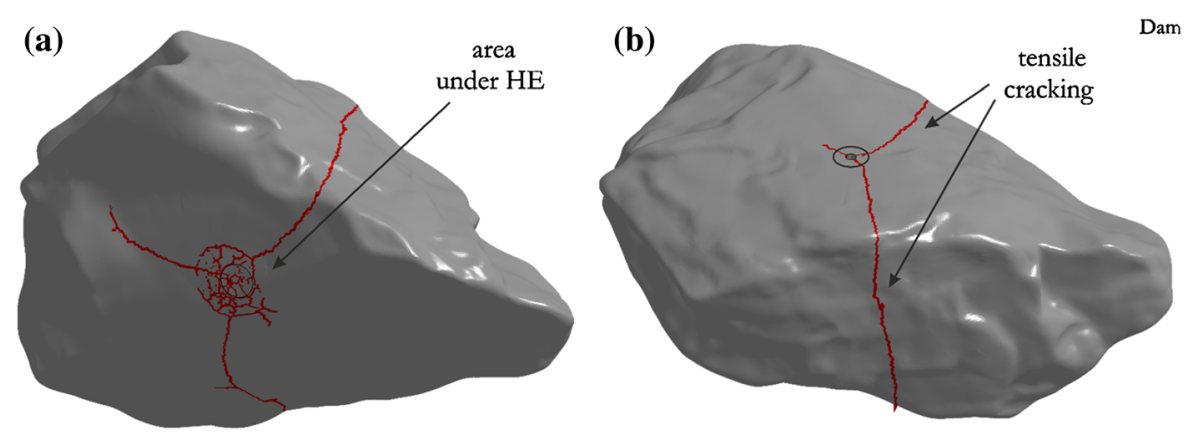

Fig. 13 Crack pattern obtained from numerical simulations of the blasting fragmentation test for sample no. 2

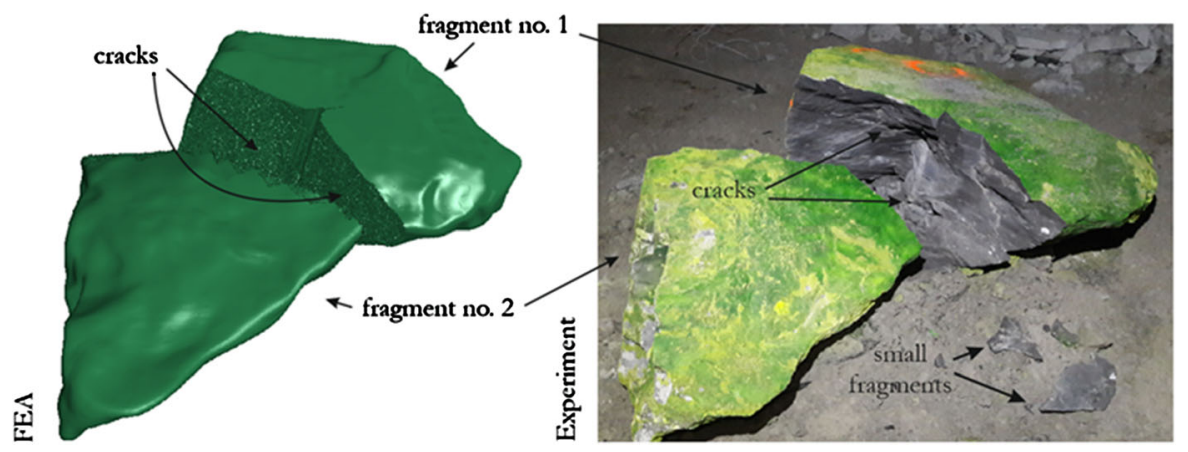

Fig. 14 Comparison of rock fragments obtained from the numerical simulation and experiment

Table 4 Comparison of the obtained fragments

\begin{tabular}{lllcc}
\hline Fragment & FEA/Exp. & Volume $\left(\mathrm{mm}^{3}\right)$ & $\%$ of the experiment & $\%$ of whole volume \\
\hline No. 1 & FEA & 0.171 & 98.85 & 36.23 \\
& Experiment & 0.173 & 100.00 & 36.66 \\
\multirow{2}{*}{ No. 2} & FEA & 0.286 & 109.16 & 60.59 \\
& Experiment & 0.262 & 100.00 & 55.51 \\
Whole & FEA/Experiment & 0.472 & 100.00 & 100.00 \\
\hline
\end{tabular}

dolomite rock. The field tests were reproduced with numerical simulations adopting explicit LS-Dyna code.

Based on the outcomes, the following conclusions can be drawn:

- Knowledge of the damping mechanism is crucial in order to obtain reliable results from numerical simulations. In this study, the Rayleigh classical approach, which is commonly used in FE dynamic analyses, was considered. Due to the difficulty of determining damping properties for rock-like materials, several values of coefficients of stiffness-weighted damping were tested. $\beta$ significantly influenced the acceleration oscillations and energy loss caused by damping. By contrast, the massweighted damping $\alpha$ only influenced lower frequencies and thus did not significantly impact the results in the present analysis. Consequently, $\alpha$ was set to 1.0 in all FEA.

- The closest agreement between the acceleration history measured in FEA and the maximum FFT magnitude was obtained at $\beta$ equal to 0.20 . The numerical simulations satisfactorily reproduced the cracking characteristics and fragmentation of both rock samples. Furthermore, the fragments from rock sample no. 2 were scanned using a 3D 
laser scanner to compare the volumes and geometries of the real-world and simulated fragments.

- The implemented JH-2 constitutive model with parameters determined for dolomite proved to be efficient and accurate for simulating the blasting and subsequent fracture and fragmentation of the rock. Nevertheless, further studies are planned to validate the model in penetration and small-scale tests. The influence of the mesh will be also analyzed in future work.

- The FEM-SPH coupled method of modelling was sufficiently effective, and the results of FEA were very similar to those of the actual tests. The main advantage of the adopted meshless approach for simulating the HE and stemming is the significantly shorter computational time compared with the ALE approach.

In future studies, the JH-2 model and the FEM-SPH method will be implemented in further numerical simulations of parallel cut-hole blasting, where a proper representation of fracture, cracking and fragmentation is crucial. Moreover, the investigations will be extended to optimize the cut-hole pattern and increase the effectiveness of the blasting method and rock fragmentation. These analyses will implement a methodology in which the fragment area is calculated based on 2D sections of the FE model and the Swebrec function is employed to fit the fragment area distribution $[19,58]$.

Acknowledgements This research was supported by the Interdisciplinary Centre for Mathematical and Computational Modeling (ICM), University of Warsaw, under grant No. GA7319. This support is gratefully acknowledged. The numerical models were prepared using Altair ${ }^{\circledR}$ HyperMesh software.

\section{Compliance with ethical standards}

Conflict of interest The authors declare that they have no conflict of interest.

Open Access This article is licensed under a Creative Commons Attribution 4.0 International License, which permits use, sharing, adaptation, distribution and reproduction in any medium or format, as long as you give appropriate credit to the original author(s) and the source, provide a link to the Creative Commons licence, and indicate if changes were made. The images or other third party material in this article are included in the article's Creative Commons licence, unless indicated otherwise in a credit line to the material. If material is not included in the article's Creative Commons licence and your intended use is not permitted by statutory regulation or exceeds the permitted use, you will need to obtain permission directly from the copyright holder. To view a copy of this licence, visit http://creativecommons.org/licenses/by/4.0/.

\section{References}

1. Pytel WM, Mertuszka PP, Jones T, Paprocki H (2019) Numerical simulations of geomechanical state of rock mass prior to seismic events occurrence-case study from a polish copper mine aided by FEM 3D Approach. In: Proc. 27th Int. Symp. Mine Plan. Equip. Sel.-MPES 2018. 417-427. https://doi.org/10.1007/978-3-319-99220-4_34

2. Mertuszka P, Szumny M, Wawryszewicz A, Fuławka K, Saiang D (2019) Blasting Delay Pattern Development in the Light of Rockburst Prevention-Case Study from Polish Copper Mine. E3S Web Conf. 105 01012. https://doi.org/ 10.1051/e3sconf/201910501012

3. Mazurkiewicz L, Małachowski J, Baranowski P, Damaziak K, Pytel W, Mertuszka P (2016) Numerical modelling of detonation in mining face cut-holes, in: Adv. Mech. Theor. Comput. Interdiscip. Issues_-3rd Polish Congr. Mech. PCM 201521 st Int. Conf. Comput. Methods Mech. C. 2015, CRC Press/Balkema, pp 393-396

4. Bocian M, Jamroziak K, Kosobudzki M (2014) The analysis of energy consumption of a ballistic shields in simulation of mobile cellular automata. Adv Mater Res 1036:680-685. https://doi.org/10.4028/www.scientific.net/AMR.1036.680

5. Kurzawa A, Pyka D, Jamroziak K, Bocian M, Kotowski P, Widomski P (2018) Analysis of ballistic resistance of composites based on EN AC-44200 aluminum alloy reinforced with $\mathrm{Al}_{2} \mathrm{O}_{3}$ particles. Compos Struct. https://doi.org/ 10.1016/j.compstruct.2018.06.099

6. Karliński J, Ptak M, Chybowski L (2019) A numerical analysis of the working machine tyre inflation process to ensure operator safety. Energies. 12:2971. https://doi.org/ 10.3390/en12152971

7. Ptak M, Blicharski Pawełand Rusiński E, Karliński J (2017) Numerical simulations of composite frontal protection system according to EC 78/2009. In: Rusiński E, Pietrusiak D (eds.) Proc. 13th Int. Sci. Conf., Springer International Publishing, Cham, pp 423-429

8. Witkowski W, Rucka M, Chróścielewski J, Wilde K (2012) On some properties of 2D spectral finite elements in problems of wave propagation. Finite Elem Anal Des 55:31-41. https://doi.org/10.1016/j.finel.2012.02.001

9. Sielicki PW, Gajewski T (2018) Numerical assessment of the human body response to a ground-level explosion. Comput Methods Biomech. Biomed Engin. https://doi.org/ 10.1080/10255842.2018.1544628

10. Arkusz K, Klekiel T, Sławiński G, Będziński R ((2019)) Pelvic vertical shear fractures: The damping properties of ligaments depending on the velocity of vertical impact load. In: AIP Conf. Proc. 2078. https://doi.org/10.1063/1. 5092080

11. Bukala J, Kwiatkowski P, Malachowski J (2017) Numerical analysis of crimping and inflation process of balloon-expandable coronary stent using implicit solution. Int. J. Numer. Method. Biomed. Eng. 33:1-11. https://doi.org/ $10.1002 / \mathrm{cnm} .2890$ 
12. Cho SH, Kaneko K (2005) Rock Fragmentation Control in Blasting. Mater Trans 45:1722-1730. https://doi.org/10. 2320/matertrans. 45.1722

13. Lewis BA (2004) Manual for LS-DYNA Soil Material Model 147, Fhwa-Hrt-04-095. 68. http://www.fhwa.dot. gov/publications/research/safety/04095/04095.pdf

14. Qu S, Zheng X, Fan L, Wang Y (2008) Numerical simulation of parallel hole cut blasting with uncharged holes. J. Univ. Sci. Technol. Beijing Miner. Metall. Mater. (Eng Ed) 15:209-214. https://doi.org/10.1016/s10058850(08)60040-7

15. Dehghan Banadaki MM, Mohanty B (2012) Numerical simulation of stress wave induced fractures in rock. Int $\mathrm{J}$ Impact Eng 40-41:16-25. https://doi.org/10.1016/j. ijimpeng.2011.08.010

16. Johansson D, Ouchterlony F (2011) Fragmentation in smallscale confined blasting. Int. J. Min. Miner. Eng. 3:72. https://doi.org/10.1504/ijmme.2011.041450

17. Lanari M, Fakhimi A (2015) Numerical study of contributions of shock wave and gas penetration toward induced rock damage during blasting. Comput. Part. Mech. 2:197-208. https://doi.org/10.1007/s40571-015-0053-8

18. Wang J, Yin Y, Esmaieli K (2018) Numerical simulations of rock blasting damage based on laboratory-scale experiments. J Geophys Eng 15:2399-2417. https://doi.org/10. 1088/1742-2140/aacf17

19. Yi C Improved blasting results with precise initiationNumerical simulation of small-scale tests and full-scale bench blasting, (n.d.). www.ltu.se

20. Zheng Z, Xu Y, Dong J, Zong Q, Wang L (2015) Hard rock deep hole cutting blasting technology in vertical shaft freezing bedrock section construction. J VibroEng 17:1105-1119

21. Yi CP, Zhang P, Shirzadegan S Numerical modelling of dynamic response of underground openings under blasting based on field tests, n.d

22. Wei XY, Zhao ZY, Gu J (2009) Numerical simulations of rock mass damage induced by underground explosion. Int J Rock Mech Min Sci 46:1206-1213. https://doi.org/10.1016/ j.ijrmms.2009.02.007

23. Hu Y, Lu W, Chen M, Yan P, Zhang Y (2015) Numerical simulation of the complete rock blasting response by SPHDAM-FEM approach. Simul Model Pract Theory 56:55-68. https://doi.org/10.1016/j.simpat.2015.04.001

24. Zhu Z, Mohanty B, Xie H (2007) Numerical investigation of blasting-induced crack initiation and propagation in rocks. Int J Rock Mech Min Sci 44:412-424. https://doi.org/10. 1016/j.ijrmms.2006.09.002

25. Bendezu M, Romanel C, Roehl D (2017) Finite element analysis of blast-induced fracture propagation in hard rocks. Comput Struct 182:1-13. https://doi.org/10.1016/j. compstruc.2016.11.006

26. Kędzierski P, Morka A, Stanisławek S, Surma Z (2019) Numerical modeling of the large strain problem in the case of mushrooming projectiles. Int J Impact Eng 135:103403. https://doi.org/10.1016/j.ijimpeng.2019.103403

27. Baranowski P, Damaziak K, Mazurkiewicz Ł, Mertuszka P, Pytel W, Małachowski J, Pałac-Walko B, Jones T (2019) Destress blasting of rock mass: multiscale modelling and simulation. Shock Vib. 2019:1-11. https://doi.org/10.1155/ $2019 / 2878969$
28. Fakhimi A, Lanari M (2014) DEM-SPH simulation of rock blasting. Comput Geotech 55:158-164. https://doi.org/10. 1016/j.compgeo.2013.08.008

29. Gui YL, Bui HH, Kodikara J, Zhang QB, Zhao J, Rabczuk T (2016) Modelling the dynamic failure of brittle rocks using a hybrid continuum-discrete element method with a mixedmode cohesive fracture model. Int $\mathbf{J}$ Impact Eng 87:146-155. https://doi.org/10.1016/j.ijimpeng.2015.04. 010

30. Gharehdash S, Barzegar M, Palymskiy IB, Fomin PA (2020) Blast induced fracture modelling using smoothed particle hydrodynamics. Int J Impact Eng 135:103235. https://doi.org/10.1016/j.ijimpeng.2019.02.001

31. Bohdal $€$ (2016) Application of a SPH coupled FEM method for simulation of trimming of aluminum autobody sheet. Acta Mech. Autom. 10:56-61. https://doi.org/10. 1515/ama-2016-0010

32. Baranowski P, Janiszewski L, Malachowski J (2014) Study on computational methods applied to modelling of pusel shaper in split-Hopkinson bar. Arch. Mech. 66:429-452

33. Świerczewski M, Sławiński G (2017) Modelling and numerical analysis of explosion under the wheel of light armoured military vehicle. Eng. Trans. 65:587-599

34. Gontarz J, Podgórski J (2019) Analysis of crack propagation in a "pull-out" test. Stud. Geotech. Mech. 41:160-170. https://doi.org/10.2478/sgem-2019-0015

35. Gontarz J, Podgórski J, Jonak J, Kalita M, Siegmund M (2019) Comparison between numerical analysis and actual results for a pull-out test. Eng. Trans. 67:311-331. https:// doi.org/10.24423/EngTrans.1005.20190815

36. Ren GM, Wu H, Fang Q, Kong XZ (2017) Parameters of Holmquist-Johnson-Cook model for high-strength concrete-like materials under projectile impact. Int. J. Prot. Struct. 8:352-367. https://doi.org/10.1177/ 2041419617721552

37. Holmquist TJ, Johnson GR, Cook WH (1993) A computational constitutive model for concrete subjected to large strains, high strain rates, and high pressures. In: 14th Int. Symp. Ballist. Quebec, Canada, Quebec, pp 591-600

38. Morales-Alonso G, Magnusson J, Hansson H, Ansell A, Gálvez F, Sánchez-Gálvez V (2013) Behaviour of concrete structural members subjected to air blast loading. In: Wickert M, Salk M (eds), Proc.-27th Int. Symp. Ballist. Ballist. 2013, DEStech Publications, Inc; Har/Cdr edition, Freiburg, pp 936-947

39. Reid JD, Coon BA, Lewis BA, Sutherland SH, Murray YD (2004) Evaluation of LS-DYNA Soil Material Model 147, Fhwa-Hrt-04-094. 85. http://www.fhwa.dot.gov/ publications/research/safety/04094/04094.pdf

40. Yi C, Sjöberg J, Johansson D (2017) Numerical modelling for blast-induced fragmentation in sublevel caving mines. Tunn. Undergr. Sp. Technol. 68:167-173. https://doi.org/ 10.1016/j.tust.2017.05.030

41. Schwer LE, Murray YD Continuous surface cap model for geomaterial modeling: A New LS-DYNA Material Type Material Technology (2) 7 th International LS-DYNA Users Conference, n.d

42. Mardalizad A, Scazzosi R, Manes A, Giglio M (2018) Testing and numerical simulation of a medium strength rock material under unconfined compression loading. J. Rock 
Mech. Geotech. Eng. 10:197-211. https://doi.org/10.1016/j. jrmge.2017.11.009

43. Malvar LJ, Crawford JE, Wesevich JW, Simons D (1997) A plasticity concrete material model for DYNA3D. Int $\mathbf{J}$ Impact Eng 19:847-873. https://doi.org/10.1016/s0734743x(97)00023-7

44. Johnson GR, Holmquist TJ (2008) An improved computational constitutive model for brittle materials, in: AIP Publishing, pp 981-984. https://doi.org/10.1063/1.46199

45. Holmquist TJ, Johnson GR, Grady DE, Lopatin CM, Hertel ES (1995) High strain rate properties and constitutive modeling of glass. In: Mayseless M, Bodner S (eds), Proc. 15th Int. Symp. Ballist., Jerusalem, Israel, pp 234-244

46. Holmquist TJ, Templeton DW, Bishnoi KD (2001) Constitutive modeling of aluminum nitride for large strain, highstrain rate, and high-pressure applications. Int J Impact Eng 25:211-231. https://doi.org/10.1016/S0734743X $(00) 00046-4$

47. Ai HA, Ahrens TJ (2006) Simulation of dynamic response of granite: a numerical approach of shock-induced damage beneath impact craters. Int J Impact Eng 33:1-10. https:// doi.org/10.1016/j.ijimpeng.2006.09.046

48. Stanislawek S, Morka A, Niezgoda T (2015) Pyramidal ceramic armor ability to defeat projectile threat by changing its trajectory. Bull. Polish Acad. Sci. Tech. Sci. 63:843-849. https://doi.org/10.1515/bpasts-2015-0096

49. Wang J, Yin Y, Luo C (2018) Johnson-Holmquist-II(JH-2) constitutive model for rock materials: parameter determination and application in tunnel smooth blasting. Appl. Sci. 8:1675. https://doi.org/10.3390/app8091675

50. Ruggiero A, Iannitti G, Bonora N, Ferraro M (2012) Determination of Johnson-holmquist constitutive model parameters for fused silica. EPJ Web Conf. 26:04011. https://doi.org/10.1051/epjconf/20122604011

51. Zhang X, Hao H, Ma G (2015) Dynamic material model of annealed soda-lime glass. Int J Impact Eng 77:108-119. https://doi.org/10.1016/j.ijimpeng.2014.11.016

52. Brown GI (1998) The Big Bang: A History of Explosives, Stroud. Sutton Pub, Gloucestershire

53. Mertuszka P, Cenian B, Kramarczyk B, Pytel W (2018) Influence of explosive charge diameter on the detonation velocity based on Emulinit 7L and 8L Bulk emulsion explosives. Cent. Eur. J. Eng. Mater. 15:351-363. https:// doi.org/10.22211/cejem/78090

54. Hallquist J (2006) LS-DYNA ${ }^{\circledR}$ theory manual, http://www. dynasupport.com/manuals/additional/ls-dyna-theorymanual-2005-beta/at_download/file

55. Liu MB, Liu GR (2010) Smoothed particle hydrodynamics (SPH): An overview and recent developments. https://doi. org/10.1007/s11831-010-9040-7

56. Mazurkiewicz L, Kolodziejczyk D, Damaziak K, Malachowski J, Klasztorny M, Baranowski P (2013) Load carrying capacity numerical study of I-beam pillar structure with blast protective panel. Bull. Polish Acad. Sci. Tech. Sci. 61:451-457. https://doi.org/10.2478/bpasts-2013-0044

57. Sielicki PW, Sumelka W, Lodygowski T (2019) Close Range Explosive Loading on Steel Column in the Framework of Anisotropic Viscoplasticity. Metals (Basel). 9:454. https://doi.org/10.3390/met9040454

58. Hallquist J (2019) LS-DYNA theory manual, livermore software technology corporation (LSTC). http://ftp.lstc.com/anonymous/outgoing/jday/manuals/ DRAFT_Theory.pdf

59. Baranowski P, Kucewicz M, Gieleta R, Stankiewicz M, Konarzewski M, Bogusz P, Pytlik M, Małachowski J (2020) Fracture and fragmentation of dolomite rock using the $\mathrm{JH}-2$ constitutive model: Parameter determination, experiments and simulations. Int J Impact Eng. https://doi.org/10.1016/j. ijimpeng.2020.103543

60. Kucewicz M, Baranowski P, Małachowski J, Trzciński W, Szymańczyk L (2019) Numerical modelling of cylindrical test for determining Jones-Wilkins-Lee equation parameters. In: Rusiński E, Pietrusiak D (eds), Proc. 14th Int. Sci. Conf. Comput. Aided Eng., Springer International Publishing, Cham, pp 388-394

61. Linforth S, Tran P, Rupasinghe M, Nguyen N, Ngo T, Saleh M, Odish R, Shanmugam D (2019) Unsaturated soil blast: flying plate experiment and numerical investigations. Int $\mathbf{J}$ Impact Eng. https://doi.org/10.1016/j.ijimpeng.2018.08. 002

62. An L, Suorineni FT, Xu S, Li YH, Wang ZC (2018) A feasibility study on confinement effect on blasting performance in narrow vein mining through numerical modelling. Int J Rock Mech Min Sci 112:84-94. https://doi.org/10. 1016/j.ijrmms.2018.10.010

63. Wang ZL, Konietzky H, Shen RF (2009) Coupled finite element and discrete element method for underground blast in faulted rock masses. Soil Dyn. Earthq. Eng. 29:939-945. https://doi.org/10.1016/j.soildyn.2008.11.002

64. Yang J, Lu W, Li P, Yan P (2018) Evaluation of rock vibration generated in blasting excavation of deep-buried tunnels. KSCE J. Civ. Eng. 22:2593-2608. https://doi.org/ 10.1007/s12205-017-0240-7

65. Toraño J, Rodríguez R, Diego I, Rivas JM, Casal MD (2006) FEM models including randomness and its application to the blasting vibrations prediction. Comput Geotech 33:15-28. https://doi.org/10.1016/j.compgeo.2006.01.003

Publisher's Note Springer Nature remains neutral with regard to jurisdictional claims in published maps and institutional affiliations. 